\title{
Sex Differences in PTSD
}

\author{
Dorte Christiansen ${ }^{1}$ and Ask Elklit ${ }^{2}$ \\ ${ }^{1}$ Aarhus University, Institute of Psychology, \\ ${ }^{2}$ National Center for Psychotraumatology, \\ University of Southern Denmark,
}

Denmark

\section{Introduction}

Research into the psychological sequalae of trauma originally started out by focusing on two sex-specific trauma populations: male war veterans with "soldier's heart", "shellshock", "battle fatigue", or "war neurosis" and female victims of sexual assault or domestic violence with "rape trauma syndrome" or "battered woman syndrome". It was noted how the flashbacks and nightmares reported by rape survivors were similar to the symptoms reported by war veterans, and several researchers and clinicians started pointing out that these trauma specific syndromes might be more similar than different (Ray, 2008; Van der Kolk, 2007). Finally, it was the large number of male Vietnam veterans and the activities of feminist and student organisations, which led to the inclusion of the first PTSD diagnosis into the American DSM-III in 1980 (American Psychiatric Association, 1980). With the introduction of the PTSD diagnosis, the idea that the male war neurosis and the female rape trauma syndrome were ultimately manifestations of the same disorder was widely accepted. As a result, most research on PTSD has been based on the idea that males and females are traumatised in similar ways, and studies on sex differences in PTSD have primarily focused on examining and explaining sex differences in the prevalence and severity of PTSD, whereas studies on sex differences in the manifestation of PTSD are almost completely absent from this otherwise expanding area of research.

Most literature on sex differences in PTSD uses the terms sex and gender interchangeably. Traditionally, however, the term sex refers to the biological distinction between males and females, whereas gender refers to the much more complex cultural understanding of masculine and feminine gender roles as they are viewed in the context of not only sex, but also culture, subculture, age, race, class, and sexual orientation. Even though many studies on PTSD claim to examine gender differences, most studies have in fact studied sex differences and only few have looked into the effect of masculinity or femininity on PTSD. Although this chapter will focus primarily on sex, we acknowledge that gender is likely to affect the development and maintenance of PTSD in males and females as well. The contribution of sex versus gender based explanations for sex differences in PTSD will be discussed throughout the chapter, although the topic merits a more thorough discussion than is possible here. 


\section{Sex differences in PTSD prevalence}

Males are exposed to more potentially traumatic events (PTE's) than females (Tolin \& Foa, 2008), particularly in adolescence and young adulthood (Norris et al., 2007). In the National Comorbidity Survey, $60.7 \%$ of males and $51.2 \%$ of females reported at least one PTE, and significantly more males than females reported exposure to more than two trauma types (Kessler et al., 1995). Despite the finding that males are more likely to experience a PTE and experience more types of PTE's than females, the female-male ratio in the prevalence of PTSD is approximately 2:1 (Tolin \& Foa, 2008) with females reporting higher levels of both re-experiencing, avoidance, and arousal (Ditlevsen \& Elklit, 2010). The lifetime prevalence of PTSD is $10.4 \%$ for females and $5.0 \%$ for males and the conditional risk across trauma types is $20.4 \%$ for females and $8.2 \%$ for males (Kessler et al., 1995). Sex differences in the prevalence of PTSD become evident early in life, peak in early adulthood, and become weakened with increased age (Ditlevsen \& Elklit, 2010; Norris et al., 2002). Across studies, the increased prevalence of PTSD in females compared to males appears to be particularly evident for lifetime PTSD (Tolin \& Foa, 2008), indicating that PTSD tends to be of longer duration in females than in males, and in the Detroit Area Survey of Trauma the median time from onset of PTSD to remission was four years for females compared to one year for males (Breslau et al., 1998).

Despite findings that sex differences in PTSD have been found across cultures and thus appear to be culturally persistent, variations regarding how pronounced such sex differences are have been reported. Norris et al. (2001) compared sex differences in a Mexican, an African-American, and an Anglo-American sample and found that sex differences in the prevalence of PTSD were amplified in the Mexican sample and attenuated in the African-American sample, with the Anglo-American sample falling in between (Norris et al., 2001). It has been suggested that sex differences in PTSD are particularly evident in communities that emphasise traditional gender roles (Norris et al., 2007). This suggests that social gender and biological sex are both important in making up such differences. Interestingly, the cross-cultural variations on sex differences appear to be more pronounced for intrusion and avoidance than for arousal symptoms, which are thought to be rooted in biological processes. It is thus possible that sex differences in arousal are primarily related to biological sex, whereas sex differences in avoidance and intrusion are also affected by social gender.

\section{Possible explanations for sex differences in the prevalence of PTSD}

\subsection{Sex differences in exposure to potentially traumatic events}

The finding that more females than males develop PTSD has been reported independently of study type, population studied, culture, type of assessment, and other methodological variables (Tolin \& Foa, 2008). Thus, the increased prevalence of PTSD in females compared to males does not appear to be simply a product of measurement error or methodological bias. Chung and Breslau (2008) conducted a latent class analysis and found no evidence of differential symptom reporting in males compared to females. This led them to the conclusion that the increased symptomatology reported by females is likely to reflect a substantive difference, rather than a sex-related reporting bias. Instead, it has been suggested that as a result of the different gender roles, which males and females hold in 
society, men and women are exposed to different stressors on a day-to-day basis (Barnyard \& Graham-Bermann, 1993; Ptacek et al., 1992). This structural theory is likely to influence not only the types of traumatic events males and females are exposed to, but also how they generally respond to such events. Thus, one possible explanation for the sex difference in the prevalence and severity of PTSD is that males and females differ in the types of trauma they experience. A well-conducted meta-analysis by Tolin and Foa (2008) found that across studies, more males than females are exposed to accidents, non-sexual assaults, combat or war, disasters, illness, unspecified injuries, and witnessing the death or injury of others. In contrast, more females experience sexual assault and childhood sexual abuse (CSA). However, it should be kept in mind that these findings are based simply on whether or not the subjects report having been exposed to the different types of PTE's. Males and females may not only be subject to different reporting bias, but may also differ in the number of times they have been exposed to each event, and such differences are unlikely to be identified in this type of meta-analysis. Thus, even though females are less likely overall to be subjected to non-sexual assaults, overall, it is possible that females who are exposed tend to be assaulted repeatedly, such as is often the case in domestic violence. It remains to be seen, whether such differences in multiple exposures to the same type of PTE add to the sex difference in PTSD prevalence. In addition to an increased risk of sexual assault, females also appear to be more exposed to betrayal trauma, in that more females than males report having been exposed to interpersonal trauma, especially assault by a perpetrator close to the victim (Goldberg \& Freyd, 2006).

Certain types of trauma (e.g. rape, CSA, combat) have been found to be more toxic (i.e. more likely to lead to PTSD) than others (e.g. accidents, bereavement; Kessler et al., 1995). It is therefore possible that the increased risk of sexual trauma in childhood, adolescence, and adulthood in females may account for differences in PTSD prevalence. However, studies have found that sex differences in PTSD prevalence persist even after trauma type is controlled, indicating that the high prevalence of PTSD in females is not simply a result of increased exposure to sexual trauma (Kessler et al., 1995; Tolin \& Foa, 2008). However, even though studies have shown that sex differences in PTSD prevalence exist across trauma types, sexual assault prior to the index trauma is rarely controlled for and may still contribute to the increased PTSD prevalence in females following new traumas. Furthermore, even within the same type of trauma, males and females may differ in the characteristics as well as their interpretation of the event (Tolin \& Foa, 2008). For example, a woman who is robbed in an isolated spot may fear that the robber will also rape her and thus have a stronger physiological reaction than a man in the same situation, who may be less likely to interpret the event as anything more than a robbery, although males as well as females may interpret the event as highly threatening and even fear for their lives.

Interestingly, studies based on military and police samples have generally failed to find an increased risk of PTSD in females compared to males (Lilly et al., 2009). Although male and female military veterans generally differ in the types of events they have been exposed to, it is also possible that the lack of reported sex difference is related to one or more variables on which police and military females differ from female civilians. Furthermore, the metaanalysis by Tolin and Foa, (2008) found that a significant sex difference in PTSD rates has not been established following adult and childhood sexual assault and abuse. This failure to discover significant sex differences in PTSD following sexual assault and abuse may be accounted for by the relatively low number of both-sex studies focusing on these two 
trauma types. Furthermore, males are more often assaulted by numerous perpetrators and sustain more physical injuries, both of which could add to the prevalence of PTSD in males compared to females (Tolin \& Foa, 2008). However, another possibility is that there may be a ceiling effect, whereby high levels of PTSD following particularly toxic traumas (e.g. sexual assault, combat) in males as well as females will overrule any specific female vulnerability to traumatic stress (Gavranidou \& Rosner, 2003). Although it is too soon to rule out this possibility, one study published after Tolin and Foa's meta-analysis found that adult female victims of childhood abuse and neglect were significantly more likely to meet criteria for a PTSD diagnosis than males (Koenen \& Widom, 2009), suggesting that sex differences may exist in these types of traumas. Even more importantly, this sex difference was reduced but not eliminated when later rape and exposure to multiple traumas were controlled for. Similarly, a Danish study found that sex remained a significant predictor of lifetime PTSD symptoms in students after rape was controlled for (O'Connor \& Elklit, 2008), although the way in which rape was assessed might have underestimated the true degree of sexual victimisation in the sample.

To sum up, although the extent of sex differences in PTSD following highly toxic trauma types needs to be studied more thoroughly, the increased risk of PTSD in females has been established across a wide variety of trauma types. Although the increased exposure of females to sexual assault and CSA may add to the sex difference in the prevalence of PTSD, differences in exposure to traumatic events do not appear to fully account for these differences. It thus appears that the structural theory is not sufficient to account for the observed sex differences in PTSD. Instead, the mediation hypothesis suggests that females are more vulnerable to PTSD, because they exhibit higher levels of certain risk factors associated with PTSD. From a gender based perspective on coping with traumatic stress, the socialisation theory holds that the way men and women are brought up and continue to be socialised in a context of gender role expectations affect how they react in the face of trauma (Ptacek et al., 1992; Rosario et al., 1988). As a result, men and women differ in the kind of events they interpret as threatening, and consequently their preferred coping strategies as well as the physiological reactions are likely to differ (Simmons \& Granvold, 2005). Thus, according to both the socialisation theory and the mediation hypothesis, sex differences in PTSD prevalence may be related to sex differences in associated risk factors in the time leading up to, during, and following the traumatic event. Next, we will focus on some risk factors, which are more pronounced in females than in males, and which according to the mediation hypothesis may help account for the increased PTSD prevalence in females. Risk factors, which are not hypothesised to add to the higher PTSD severity in females, compared to males (e.g. social support, prior trauma exposure) will not be discussed here.

\subsection{Sex differences in risk factors related to the development of PTSD \\ 3.2.1 Pre-traumatic risk factors}

It has been suggested that the higher degree of negative affectivity in females may result in more reactive emotional and somatic responses in females compared to males (Zeidner, 2006). The overlapping constructs of negative affectivity and neuroticism have been defined as the propensity to experience a wide variety of somatic and emotional dysphoric states including depression, anxiety, anger, and somatic symptoms (Kirmayer et al., 1994). High levels of neuroticism have been shown to increase sensitivity to stressful life events (Kendler et al., 2004). Furthermore, neuroticism and negative affectivity have been shown to play a role in the development of PTSD (Ahern et al., 2004) as well as in other psychiatric 
disorders, including depression and anxiety disorders (Hettema et al., 2004; Kendler et al., 2004). The influence of negative affectivity on all three disorders may explain, why both anxiety and depression have been found to be related to PTSD (Kessler et al., 1995). Females have been reported to score higher than males on measures of neuroticism (Hettema et al., 2004; Lynn and Martin, 1997) and negative affectivity (Joiner \& Blalock, 1995), and both anxiety and depression are more commonly found in females than in males (Kessler et al., 1994). It could therefore be hypothesised that the higher prevalence of PTSD in females is a result of their higher negative affectivity/neuroticism as well as pre-existing anxiety and depression. One study has reported that the higher risk of PTSD in females in the general population was mainly due to their exposure to more toxic trauma types in combination with a higher prevalence of pre-existing psychiatric disorders (Hapke et al., 2006). However, Spindler et al. (2010) found that even though sex was no longer significantly associated with PTSD status after trait anxiety was controlled for, there was still a trend towards significance, and Fullerton et al. (2001) found that neither prior PTSD, major depression, nor other anxiety disorders could account for the increased PTSD prevalence in females. Finally, Breslau et al. (1997) found that although prior depression and anxiety disorder did reduce the sex difference in PTSD prevalence, they did not eliminate it. Thus, at the present time there is not convincing evidence that sex differences in PTSD can be fully accounted for by negative affectivity/neuroticism and pre-existing symptomatology.

\subsubsection{Peritraumatic risk factors}

In relation to the risk factors related directly to the traumatic event, sex differences have been widely reported in primary appraisal, and it has been suggested that the higher risk for stress-related disorders in females may be due to such differences. The A2 criterion of the DSM-IV PTSD diagnosis states that in order for an event to be considered traumatic, the person must have experienced intense fear, horror, or helplessness (American Psychiatric Association, 2000). Females have generally been found to be more likely than males to report such feelings in response to a PTE (Irish et al., 2011; Norris et al., 2002). Another common peritraumatic experience is dissociation, which is defined as a disruption in the usually integrated functions of consciousness, memory, identity, and perception (American Psychiatric Association, 2000). Dissociative reactions during or following a traumatic event have been found to be important risk factors for PTSD (Ehring et al., 2006; Ozer et al., 2003). Although there do not appear to be major sex differences in the prevalence of dissociative reactions in the general population (Spitzer et al., 2003), several studies have reported higher levels of trauma-related dissociation in females compared to males (Bryant \& Harvey, 2003; Irish et al., 2011). It is thus possible that sex differences in such peritraumatic rections may account for sex differences in PTSD prevalence.

It has been suggested that the professional training of police officers, which is in accordance with a traditionally masculine minimisation of emotional reactivity, can account for the previously mentioned lack of reported sex differences in PTSD prevalence in police samples (Pratchett et al., 2010), which appears to be caused by a lower degree of traumatisation in female police officers compared to female civilians. Lilly et al. (2009) compared female police officers to female civilians and found that despite a higher degree of traumatic exposure, female police officers reported lower levels of PTSD. This could be accounted for by lower levels of peritraumatic emotional distress in the police officers. However, although female police officers also reported lower levels of peritraumatic dissociation, this did not 
account for any additional difference in PTSD levels. In contrast, Irish et al. (2011) found that perceived life threat could not account for sex differences in PTSD severity after an MVA, but that peritraumatic dissociation served as a partial mediator of 6 week and 6 month PTSD severity. Finally, Spindler et al. (2010) found that sex was no longer significantly associated with PTSD status in a logistic regression analysis after perceived life threat was controlled for, whereas two other studies have found that neither peritraumatic dissociation or perceived threat (Ehlers et al., 1998) nor peritraumatic helplessness or horror (O'Connor \& Elklit, 2008) could eliminate sex as a risk factor for PTSD. Thus, contradictory findings have been reported on whether sex differences in peritraumatic reactions can account for sex differences in PTSD.

\subsubsection{Post-traumatic risk factors}

When it comes to post-traumatic risk factors associated with PTSD, sex differences in the use of coping strategies have been repeatedly reported. Females tend to use more emotionfocused coping strategies, such as support seeking, than males (e.g. Tamres et al., 2002). Furthermore, although males do not use any coping style more often than do females, overall, they do appear to use relatively more problem-focused and avoidance coping than females (Tamres et al., 2002), and they are more likely than females to choose problemfocused coping as their initial coping strategy (Ptacek et al., 1992). Whereas a problemfocused coping style has shown to serve as a protective factor against PTSD, both avoidant and emotion-focused coping have been reported to be related to increased PTSD severity (Bödvarsdóttir \& Elklit, 2004; Gil, 2005). It is thus possible that the use of emotion-focused coping may to some degree account for the increased prevalence of PTSD in females (Peirce et al., 2002). However, O'Connor \& Elklit (2008) found that neither problem-focused nor avoidant coping was significantly associated with lifetime PTSD severity, and that sex remained a significant predictor of PTSD severity after emotion-focused coping was controlled for.

In addition to differences in coping strategies, females are more likely to blame themselves for the trauma and to see themselves and the world in a negative light following a PTE, and such post-traumatic cognitions have been found to predict PTSD (Cromer \& Smyth, 2010). Thus, it could be expected that sex differences in post-traumatic cognitions may help account for the increased rate and severity of PTSD in females compared to males. However, one study found that self-blame and negative cognitions about the world and oneself failed to account for sex differences in students' PTSD symptoms (Cromer \& Smyth, 2010). And another study reported that although sex was no longer significantly associated with PTSD symptoms after the same three post-traumatic cognitions and interactions with sex had been controlled for, negative cognitions about oneself was actually more strongly associated with PTSD symptoms in males than in females, suggesting that such post-traumatic cognitions in females are unlikely to account for sex differences in PTSD severity.

\subsection{Evaluation of the mediation hypothesis}

Together, the structural and socialisation theories offer a valid gender-based approach to sex differences in PTSD. However, gender influences are generally very difficult to discern from sex differences and can often be equally well explained by biologically based theories. For example, it was reported that a traditionally masculine response style could at least partly explain why female police officers reported lower levels of PTSD than female civilians, and 
it was suggested that such differences were due to the masculine socialisation of police officers (Lilly et al., 2009). However, it could be argued that the women who choose to become police officers already differ from women who do not on a number of variables relevant to the development of PTSD. Such differences (which may be accounted for either by prior socialisation processes or differences in hormone levels and other physiological factors) may account for the similar PTSD prevalence found in male and female police officers better than any police-specific socialisation processes.

In sum, sex differences in the risk factors associated with PTSD may account for at least part of the increased prevalence of PTSD in females, and several studies have shown that when included in hierarchical regression models, sex often becomes non-significant after other variables are controlled for. This has led many researchers to conclude that the role of sex in PTSD research is not as important as has previously been assumed (e.g. Ozer et al., 2003). However, other studies have found that sex remains a significant predictor of PTSD severity even after risk factors, which are more prevalent in females have been controlled for (e.g. Ehlers et al., 1998, O'Conner \& Elklit, 2008). In order to fully test the mediation hypothesis, specific mediation studies need to be conducted, which make an effort to include all risk factors known to be more prevalent in females. However, research on sex differences in PTSD is still in its childhood, and viewing sex simply as a risk factor or as a control variable may be too simplistic. We believe that sex differences in PTSD go much deeper than simple mediation effects. In addition to sex differences in the prevalence of PTSD, sex differences may also exist in the physiological response to trauma and in how such reactions may shape symptom development. The latter part of this chapter will focus on these less studied sex differences in PTSD.

\section{Sex differences in initial trauma response}

It is generally accepted, that confrontation with a stressor results in immediate activation of the sympathetic nervous system (SNS) and release of the catecholamines epinephrine and norepinephrine, which encourage either fighting or fleeing behaviour. The activation of the SNS further stimulates the slower stress response of the hypothalamic-pituitary-adrenal (HPA) axis. This triggers the release of corticotropin releasing hormone (CRH), adrenocorticotropin hormone (ACTH), and glucocorticoids, particularly cortisol. However, the physiological stress response in males has been much more extensively studied than is the case for females (Peirce et al., 2002). Furthermore, both-sex studies are often based on small samples without sufficient power to detect sex differences. This is highly problematic because important sex differences have been reported in the HPA response to stress (Kirschbaum et al., 1999).

Arginine vasopressin (AVP) and oxytocin are two peptide hormones induced by the HPA axis. Even though AVP and oxytocin are structurally similar and differ from each other by only two amino acids (Klein \& Corwin, 2002), the two hormones differ widely in the roles they play in response to stress. Whereas AVP stimulates the fight-or-flight response and HPA axis activation (Klein \& Corwin, 2002), oxytocin appears to suppress the HPA response to stress and be regulated by the parasympathetic nervous system (PNS; Klein \& Corwin, 2002; Neumann, 2008; Neumann et al., 2000). AVP levels are higher in males than in females and may be regulated by testosterone (Rasmusson et al., 2002). In contrast, oxytocin levels are higher in females, and the bio-behavioural effects of oxytocin are enhanced by oestrogen (Klein \& Corwin, 2002). Furthermore, there is preliminary evidence that the two female sex 
hormones oestrogen and progesterone are associated with blunted vascular reactivity to acute stressors (Peirce et al., 2002). Thus, oxytocin appears to play a greater role in females compared to males, and as a result females may be more prone to react to acute stress with a suppression of the HPA axis and the SNS in response to stress. In contrast, higher levels of AVP in males are associated with increases in HPA and SNS activity in the face of threat, consistent with a fight-or-flight response. This apparent sex difference is supported by the finding that males appear to respond to stressful events with greater increases in cortisol than do females, which may reflect a tendency to HPA hyper-reactivity in males and hyporeactivity in females (Kudielka \& Kirschbaum, 2005).

Taylor et al. (2000) have suggested that whereas males respond to stress with the wellknown fight-or-flight system regulated by the SNS, evolutionary demands have favoured an alternative tend-and-befriend system in females regulated by the PNS. This alternative response to stress is hypothesised to have developed because it has been more adaptive for females in times of threat to tend to offspring and seek protection among other members of the group. The tend-and-befriend system is hypothesised to be linked to oxytocin, which is implicated in a variety of social behaviours relevant to how females respond in the aftermath of trauma, including social support and coping (Taylor, 2006; Taylor et al., 2002). In support of the tend-and-befriend theory, it has been documented that males generally respond to stressful events with physiological hyperarousal and an increase in aggressive behaviours, whereas females are more likely to group together and seek social support especially from other females (Taylor et al., 2000). Kivlighan and colleagues (2005) found that activation of the HPA axis evidenced by increases in cortisol levels in preparation for a rowing competition was associated with increased competitiveness and more pre-race mental preparation in males but with bonding and social affiliation with teammates in females. Furthermore, a study of 18-month-old children has reported sex differences in the response to frightening maternal behaviour (David \& Lyons-Ruth, 2005). Whereas males responded by displaying pronounced avoidance, resistance, and conflict behaviour, females responded by approaching their mothers while simultaneously displaying behaviours such as hesitation, fearfulness, and freezing. In accordance with this dissociation-like behaviour in female toddlers, adult females use more dissociative mechanisms in the face of trauma compared to males (Bryant \& Harvey, 2003; Irish et al., 2011). Dissociation appears to be linked to a suppression of activity in the sympathetic nervous system and the HPA axis (Olff et al., 2007).

Some of the differences in the male and female response to stress, which have been discussed here, appear to be best explained by biological sex differences. For instance, several of the hormones involved in HPA activation appear to be affected by the female menstrual cycle (Kudielka \& Kirschbaum, 2005), and sex differences in the physiological response to stress appear to be present very early in life (David \& Lyons-Ruth, 2005; Kudielka \& Kirschbaum, 2005). However, depression research has indicated ways in which both environmental and genetic factors can lead to changes in HPA reactivity (Swaab et al., 2000), and studies indicate that sex differences in the epinephrine response to cognitive challenge is mediated by gender role (Davis \& Emory, 1995). Further support for the influence of gender roles can be found in one study, which reported that confrontation with achievement challenges involving performance failures resulted in increased free cortisol levels in males but not in females (Kudielka \& Kirschbaum, 2005). In contrast, social rejection challenges resulted in significant increases in females, but not in males, indicating that different stressors may lead to activation of the HPA axis in males and females. This 
suggests that gender roles may affect, which characteristics of an event are considered stressful by males and females and such differences affect the psychobiological stress response and may further affect the risk of developing PTSD. Thus, even though the fightor-flight system exists in females, the tend-and-befriend system is assumed to dominate in times of danger. However, despite sex differences in the normal response to trauma, it is important to note that there are intra-sex differences. Geary and Flynn (2002) have pointed out that males do not always react to stress with fight-or-flight behaviour and that in some situations males respond to stress in ways similar to the tend-and-befriend response in females. With the tend-and-befriend and the fight-or-flight system operating in both sexes, intra-sex differences in the initial trauma response are likely to depend upon intra-sex variations in hormone levels as well as socialisation and gender role expectations.

Little is known about which factors contribute to the shift from adaptive responses during and immediately following the traumatic event to maladaptive responses, which may be related to PTSD in the long run (Paris et al., 2010). However, it is likely that sex differences in the initial stress response may persist beyond the traumatic event and affect the development and maintenance of PTSD. Perry and colleagues (1995) have suggested that neural responses to stress may become sensitised, resulting in the same neural responses being elicited by decreasingly intense stimuli. The tend-and-befriend versus fight-or-flight theory proposed by Taylor and colleagues may thus be highly relevant to include in a theory of sex differences in PTSD, as it is possible that sex differences in the initial response to trauma may lead males and females to follow different pathways to PTSD, as has previously been suggested (Christiansen \& Elklit, 2008).

\section{Sex-specific pathways to PTSD}

Perry and colleagues (1995) suggested that two neuronal response patterns could be identified in traumatised children. The first behaviour pattern was assumed to be associated with a sensitisation of the catecholamine system (in accordance with increased activation of the SNS) resulting in hyperarousal in response to traumatic reminders. The other behaviour pattern was assumed to be associated with a decrease in blood pressure and heart rate (consistent with a down-regulation of the SNS). This latter behaviour pattern was initiated by an attempt to seek protection from the caretaker, which in the case of persistent threat was followed by a range of more and more dissociative symptoms, including compliance, freezing, and complete dissociation (Perry et al., 1995). In accordance with this theory, two separate pathways to PTSD have been identified in a study of child burn victims (Saxe et al., 2005). One pathway was mediated by dissociation, the other by anxiety/arousal. The two pathways were separated by different risk factors, suggesting that different bio-behavioural systems may be involved in the development and maintenance of PTSD. More specifically, the anxiety/arousal pathway is likely to be related to the fight-or-flight system controlled by the SNS and the HPA axis, whereas the dissociation pathway may be connected to the animal "freeze" response, which appears to be controlled by the PNS (Saxe et al., 2005). This study did not report any sex differences in the two pathways, but another study focusing on sexually abused children found support for the existence of an anxiety/arousal pathway and a dissociation pathway as well as a third avoidance pathway, which was more pronounced in boys than in girls (Kaplow et al., 2005).

We do not know of any studies examining the existence of different pathways to PTSD in adults. However, the argument that the anxiety/arousal pathway should be linked to an 
activation of the HPA axis and the SNS corresponds to the male stress response proposed above. Similarly, the idea that the dissociation pathway should be linked to the PNS is in accordance with the female stress response. There thus appears to be some overlap between the findings concerning different pathways to PTSD in children and sex differences in the initial stress response in adults. This suggests, that even though the two studies on pathways in children did not report any sex differences in the anxiety/arousal and dissociation pathways, males may be more likely to follow an anxiety/arousal pathway and females a dissociation pathway to PTSD. This is in accordance with the ideas proposed by Perry et al. (1995), who argued that activation and sensitisation of the dissociative response pattern was more common in females than in males, whereas the opposite appeared to be the case for the hyperarousal pattern. Furthermore, although the avoidance pathway identified in the study by Kaplow et al. (2005) was not associated with a specific physiological system, it could be argued that avoidance is a form of fleeing behaviour associated with the fight-or-flight system (Taylor, 2006), and as this pathway was more pronounced in boys than in girls, males may also be more likely to follow an avoidance pathway than females.

If males and females follow different pathways to PTSD, we would expect to find sex differences in the relationship between certain risk factors and PTSD. Whereas research has mainly focused on mediation effects between sex and PTSD, the moderation hypothesis states that there may be sex differences in the relationship between different risk factors and symptomatology (Stone et al., 2010), suggesting that some risk factors may predict PTSD in females but not in males, whereas others may better predict PTSD in males. Furthermore, if such sex-specific pathways are related to the fight-or-flight versus tend-and-befriend response to stress, we would hypothesise that particularly behaviours related to either the tend-and-befriend or the fight-or-flight response to stress would show sex differences in their ability to predict PTSD. For example, physiological processes involved in the tend-andbefriend response, such as activation of the PNS and the role of oxytocin, could make emotion-focused coping, particularly support seeking, social support, and possibly dissociation more closely related to PTSD in females than in males. In contrast, arousal, anxiety, and possibly problem-focused and avoidant coping strategies could be hypothesised to be more important in the development or prevention of PTSD in males compared to females.

\section{Sex as a moderator}

\subsection{Social support}

Empirical evidence suggests that high levels of oxytocin may enhance the effect of social support on stress (Taylor et al., 2006), suggesting that the tend-and-befriend response may not only affect how females respond to stress, but may also affect how they benefit from social support in the aftermath of trauma. Not only do females seek, receive, and provide more support in stressful situations than males (Andrews et al., 2003; Tamres et al., 2002), there are also some indications that the positive effects of social support as well as the negative effects of negative social attention on PTSD may be more pronounced in females than in males (Ahern et al., 2004; Andrews et al., 2003; Gavrilovic et al., 2003). However, other studies have not found this (Farhood et al., 1993), and the relationship between sex, social support, and PTSD appears to be complex (Christiansen \& Elklit, 2008). In order to test the hypothesis that sex moderates the impact of social support on PTSD, we conducted 
a number of new analyses on previously published data based on two separate samples (see Christiansen \& Elklit, 2008). One sample consisted of residents in an area, which had been almost completely destroyed by an industrial disaster (the explosion sample), the other consisted of high school students who had witnessed a stabbing incident, were a young girl was killed (the high school sample). In contrast to the original analysis, this time we used only the symptoms included in the DSM-IV to measure PTSD severity (i.e. the first 17 items of the Harvard Trauma Questionnaire; Mollica et al., 1992). As can be seen in Table 1, we found no significant sex differences in correlations between feeling let down by others and PTSD severity, and positive social support was unrelated to PTSD severity in both males and females in the explosion sample. However, we did find that positive social support was significantly more strongly correlated with PTSD severity in females compared to males in the high school sample. There thus appears to be some support for the hypothesis that sex moderates the relationship between social support and PTSD.

\begin{tabular}{|l|c|c|c|r|r|r|r|}
\hline & $\begin{array}{c}\text { Positive } \\
\text { support }\end{array}$ & $\begin{array}{c}\text { Feeling } \\
\text { let down }\end{array}$ & Dissociation a & Anxiety & $\begin{array}{c}\text { Em. } \\
\text { cop. }\end{array}$ & $\begin{array}{c}\text { Probl. } \\
\text { cop. }\end{array}$ & \multicolumn{1}{c|}{$\begin{array}{c}\text { Avoi. } \\
\text { cop. }\end{array}$} \\
\hline Males & $-.18 /-.05$ & $.50^{* *} / .33^{* *}$ & $.56^{* *} / .44^{* *}$ & $.73^{* *}$ & $.66^{* *}$ & -.02 & $.32^{* *}$ \\
\hline Females & $-.14 /-.35^{* *}$ & $.36^{* *} / .45^{* *}$ & $.62^{* *} / .68^{* *}$ & $.57^{* *}$ & $.75^{* *}$ & -.16 & $.27^{*}$ \\
\hline$z$ & n.s. $/ 2.51^{*}$ & n.s. $/$ n.s. & n.s. $/-2.96^{* *}$ & $1.73 \mathrm{~b}$ & n.s. & n.s. & n.s. \\
\hline
\end{tabular}

Pearson coefficients between risk factors and PTSD severity (combined score on the 17 first HTQ items) are shown separately for males and females from the explosion study and the high school stabbing incident.

${ }^{a} \mathrm{r}$ values from the explosion study / $\mathrm{r}$ values from the stabbing incident study ${ }^{*} p<.05$; ${ }^{* *} \mathrm{p}<.01$;

${ }^{\mathrm{b}} p=.08 ;$ n.s.: not significant

Em. cop.: emotion-focused coping; rat. cop.: rational coping; Avoi. cop.: avoidance coping.

Table 1. Correlations between risk factors and PTSD severity for males and females

The impact of sex on the relationship between social support and PTSD is further complicated by the possibility that different types of support may have differential impact on PTSD symptomatology in males and females. For example, it is possible that talking about the traumatic event may be preferable for females, whereas males may appreciate practical assistance more, because such types of support are most compatible with the preferred coping strategies used by each sex. Furthermore, males as well as females depend mostly on female providers of support, and whereas females often have multiple support sources, adult males often cite their spouses as their only confidantes (Shumaker \& Hill, 1991). This may be the reason why being unmarried serves as a risk factor for mortality in males to a greater extent than is the case for females (Shumaker \& Hill, 1991). Thus, whereas females may be more vulnerable to lack of support and negative reactions from others more generally, males may be more dependent on the support of their spouse and thus be relatively more vulnerable to PTSD in case of separation or spousal bereavement. In accordance with this idea, a study on elderly bereaved has reported a lack of sex differences in PTSD severity (Elklit \& O'Connor, 2005), which is in contrast to the otherwise wellestablished increased prevalence of PTSD among females.

\subsection{Anxiety/arousal}

The apparent role of AVP in the acute male stress response points to the possibility that arousal may predict PTSD in males more strongly than in females, and that males may be 
more prone to follow the anxiety/arousal pathway to PTSD. As a result, we would expect that anxiety as well as arousal during or immediately following a traumatic event would be stronger predictors of PTSD in males than in females. One study has found that a preexisting anxiety disorder predicted PTSD in males, but not in females (Bromet et al., 1998), and a study on survivors of an industrial accident found that anxiety levels measured three months after the incident were significantly related to PTSD one year later in males, but not in females (the explosion study; Christiansen \& Elklit, 2008). Furthermore, as can be seen in Table 1, new analyses revealed that there was a non-significant trend towards anxiety being more highly correlated with PTSD severity in males compared to females $(\mathrm{r}=.73$ vs. $\mathrm{r}=.57$; $\mathrm{z}=.73 ; \mathrm{p}=.08$; unpublished analyses). Finally, a study of PTSD in MVA victims found that the interaction between sex and prior anxiety disorder was not significant (Fullerton et al., 2001).

Arousal in the acute aftermath of trauma has primarily been studied in MVA victims. Two studies (Bryant et al., 2000; Shalev et al., 1998) have reported that increased heart rate, but not blood pressure, measured in the emergency department following an MVA was associated with later PTSD. In contrast, Blanchard et al. (2002) found that increased heart rate was associated with lower levels of PTSD. Interestingly, both studies, which found heart rate to be positively associated with later PTSD, were based on predominantly male samples, whereas Blanchard and colleagues based their results on a predominantly female sample. Furthermore, the relationship between lower heart rate and later PTSD was significant only in females (Blanchard et al. 2002). It is possible, that the lack of significance in males was due to the low number of male participants, but another possibility is that decreased heart rate measured in the emergency room was associated with later PTSD in females but not males because of a suppressed HPA and SNS response and increased rates of dissociation in females. It is thus possible that the results reflect the existence of different pathways leading to PTSD in males and females. Finally, one study examining the influence of HPA hormones on PTSD separately in males and females found that increased levels of epinephrine, norepinephrine, and cortisol were related to PTSD status in males, but not females, one month after an MVA (Hawk et al., 2000). Thus, there are some indications that anxiety and particularly physiological arousal may be more strongly related to PTSD in males than in females.

\subsection{Dissociation}

To the best of our knowledge, no study to date has examined a possible role of oxytocin in dissociative responses. However, there are some arguments for a possible role of oxytocin in dissociation. First, dissociation appears to be associated with a down-regulation of the HPAaxis (Olff et al., 2007) as well as a reduced heart rate, consistent with a down-regulation of autonomic reactivity (Griffin et al., 1997). This is consistent with the effects of oxytocin on the SNS and HPA-axis. Secondly, in the above mentioned study by Bryant and colleagues (2000) on MVA victims, acute stress disorder (ASD) was associated with a lower heart rate compared to subclinical ASD without dissociation, indicating that dissociative reactions may suppress SNS arousal, just as oxytocin appears to do. Finally, David and Lyons-Ruth (2005) reported that when faced with frightening maternal behaviour, female toddlers reacted with affiliative behaviour in combination with inhibition of all other behaviour, consistent with the freeze response. These findings are in line with the ideas of Perry and colleagues (1995), that dissociation in children is associated with help-seeking behaviour. 
Such results suggest that dissociative reactions in the female stress response may coexist with affiliative behaviour, in which the role of oxytocin has repeatedly been demonstrated (Taylor, 2006; Taylor et al., 2002).

Not only do females report higher levels of traumatic dissociation than do males, peritraumatic dissociation also appears to be a stronger risk factor for PTSD in females. An initial diagnosis of ASD, which is very much based on the presence of dissociation, has been reported to be a more accurate predictor of PTSD in females than in males, and it has been suggested that this can be explained by an increased prevalence and predictive power of persistent dissociation in females compared to males (Bryant \& Harvey, 2003). Similarly, peritraumatic dissociation has been found to predict higher levels of PTSD in female but not male victims of both motor vehicle accidents (Fullerton et al., 2001) and an industrial disaster (the explosion sample; Christiansen \& Elklit, 2008). However, in the latter study, new correlation analyses revealed that although dissociation appeared to be more strongly related to PTSD severity in females than in males (see Table 1), this difference was not significant. Furthermore, dissociation was reported to significantly predict PTSD severity in both males and females in a study of Palestinians (Punamäki et al., 2005) and in a study of adolescents who witnessed a stabbing incident (the high school sample; Christiansen \& Elklit, 2008). However, in the latter study, further analyses shown in Table 1 revealed that although there were no significant sex differences after other variables had been controlled for, dissociation and PTSD severity were more strongly correlated in females than in males in a simple correlation analysis $(\mathrm{r}=.68$ vs. $\mathrm{r}=.44 ; \mathrm{z}=-2.96 ; \mathrm{p}=.003$; unpublished analyses). This suggests that there may be at least a partial moderation effect of gender on the relationship between dissociation and PTSD.

\subsection{Coping}

Banyard and Graham-Bermann (1993) have criticised that female coping, and particularly the efficacy of coping in females, have only been studied based on theories of what constitutes adaptive coping in males, and that this has often led to the conclusion that females are inferior copers compared to males. They further criticise coping studies of being almost exclusively conducted on male samples. Although the field of coping and stress research is no longer as deserving of this critique as it used to be, the possibility of sex differences in coping efficacy is still largely ignored in the coping literature and research. However, it is possible that different coping styles are effective for males and females in different situations. Both oxytocin and AVP have been linked to the long-term effects of stress on coping (Neumann et al., 2000), and these two hormones may thus be involved in sex differences in the use of different coping strategies.

The tend-and-befriend response is in its nature related to coping through support seeking, which tends to be categorised as an emotion-focused coping strategy, although seeking practical support is often categorised as a problem-focused strategy. In contrast, Taylor (2006) has linked the use of avoidance coping strategies to the fight-or-flight response. Furthermore, whereas avoidance coping may be viewed as a form of fleeing behaviour, it could be argued that problem-focused or rational coping is a form of fighting behaviour. As a result, we hypothesise that emotion-focused coping, particularly support seeking may be more adaptive in females, whereas problem-focused and avoidant coping may be more strongly associated with PTSD in males. In accordance with this hypothesis, studies, which have evaluated the relationship between coping and psychopathology separately for males 
and females, have generally found important sex differences (Hovanitz \& Kozora, 1989). Although this has not been examined specifically for PTSD, there is some support that problem-focused coping may be more adaptive for males, whereas emotion-focused coping may be less maladaptive for females than has been found for males (Hovanitz \& Kozora, 1989). Furthermore, emotion approach coping, which is a certain kind of emotion-focused coping involving active processing and expression of emotions, has been shown to decrease depression and increase life satisfaction in females, but to have the opposite effect on males (Folkman \& Moskowitz, 2004). In contrast, problem-focused coping has been reported to be generally more adaptive for males (Tamres et al., 2002). Although coping was not included in the original analyses by Christiansen \& Elklit (2008), new analyses based on data from the explosion study showed that emotion-focused and avoidant coping were associated with higher PTSD levels in both males and females, whereas rational coping was not associated with PTSD severity for either sex (see Table 1). Z-tests revealed no significant sex differences.

Thus, although there is some support for the hypothesis that different coping strategies may be adaptive for males and females in relation to symptomatology in general, this has not been documented in relation to PTSD. Furthermore, the studies mentioned above, which have found sex differences in the effectiveness of coping have generally focused on more specific coping strategies rather than broader coping styles, such as emotion- or problemfocused coping. This may suggest, that such coping styles include strategies, which are too heterogeneous for the detection of moderation effects. In particular, we find it problematic that emotion-focused coping is often operationalised to include both behaviours which would normally be considered positive, such as seeking social support, and behaviours which are more likely to represent symptomatology, such as rumination (Stanton, DanoffBurg, Cameron, \& Ellis, 1994). In fact, in the new analyses introduced above, in which we found emotion-focused coping to be significantly and positively related to PTSD severity in both males and females, the questionnaire used to assess coping (a revised version of the Coping Style Questionnaire; Elklit, 1996) did not include any items on support seeking behaviour. In order to shed more light on sex differences in the relationship between emotion-focused coping and PTSD, future studies should look more closely at which specific emotion-focused behaviours may be more adaptive for females than for males.

The question of whether sex moderates the effect of coping on symptomatology becomes even more complex when one considers that the efficacy of different coping styles may depend upon the characteristics of the situation in question. Araya et al. (2007) examined mental distress and quality of life in a sample of internally displaced Ethiopians and found that the relationship between coping and mental distress varied not only by sex but also by degree of trauma exposure. For males, emotion-focused coping was associated with higher levels of mental distress only when trauma exposure was high, whereas for females, emotion-focused coping was only significantly associated with higher levels of symptomatology when exposure was low (J. Chotai, personal communication; see also Araya et al., 2007). This suggests, that for women who have been repeatedly traumatised, emotion-focused coping may not be maladaptive, whereas that appears to be the case for men who have been exposed to multiple trauma. Although the study did not specifically examine PTSD symptoms, it is possible that a similar relationship between sex, degree of exposure, and emotion-focused coping exists for PTSD. Furthermore, because the doseresponse model of trauma may refer to both repeated exposure and exposure to more toxic 
trauma types (Elklit \& Christiansen, in press), it is possible that this relationship holds true not only for number of traumatic events but also for severity of traumatic events. Many studies on the relationship between coping and PTSD examine coping across situations in general, instead of specifically in relation to the traumatic event. As the preference, and especially the efficacy, of different coping strategies are likely to differ according to the characteristics of the situation at hand, studies which assess coping in relation to the specific traumatic event may be best suited to illuminate the complex relationship between coping and PTSD in males and females.

\subsection{Evaluation of the moderation hypothesis}

To sum up, there is some support for the moderation hypothesis, although results are inconsistent. Studies indicate that peritraumatic physiological arousal may be predictive of later PTSD in males but not in females. There is also some support that peritraumatic and persistent dissociation are more predictive of later PTSD in females. Bryant et al. (2000) found that later PTSD status was best identified through either increased heart rate or a diagnosis of ASD, indicating that two distinct pathways may lead to PTSD. There is thus some support for the hypothesis that males may primarily follow an arousal pathway and females a dissociation pathway to PTSD, although these findings are only preliminary and more research is needed. Some support was also found for a moderation effect on social support and PTSD. Although the association between social support and PTSD was stronger in females than in males, consistent with the tend-and-befriend theory and the greater role of oxytocin in females, it is unknown how such findings relate to the proposed sex-specific pathways to PTSD. One possibility is that the positive effects of social support and the negative effects of dissociation are somehow combined in the dissociation pathway to PTSD, possibly because dissociation occurs when tend-and-befriend behaviour proves ineffective, as suggested by Perry et al. (1995). However, another possibility is that lack of social support may represent an independent pathway to PTSD. Furthermore, support for the moderation hypothesis did not appear to be as strong for anxiety as was the case for arousal. It has been suggested that physiological arousal associated with the fight-or-flight system is related to fear but not anxiety (Grillon, 2008). It is therefore possible that anxiety and physiological arousal may not be combined in a single pathway to PTSD, but may instead represent similar but independent pathways. Finally, there was not much support for the moderation hypothesis in relation to coping. It is thus possible, that if the avoidance pathway can be found in adults, it may not be moderated by sex.

Figure 1 shows a preliminary model of how sex differences in the acute response to trauma may affect the development of PTSD. It is hypothesised that exposure to a traumatic stressor results in activation of the SNS in both sexes. However, once the SNS has activated the HPA axis, sex differences in the stress response begin to show. In males, the SNS response is amplified by AVP, which is secreted as part of the HPA response and fuelled by testosterone. This sustained activation of the SNS and increased activity in the HPA axis prepares the body for fighting or fleeing. If the SNS and the HPA axis are not downregulated and brought back to homeostasis, this fight-or-flight response may persist and make up one or more pathways to PTSD. Such pathways are hypothesised to be mediated by physiological arousal and anxiety and possibly by avoidance coping, and problem-focused coping. In contrast, HPA activation in females is associated with the secretion of oxytocin, the effects of which are amplified by oestrogen. Oxytocin is assumed 
to suppress SNS and HPA activity and instead be associated with activation of the PNS. This triggers the tend-and-befriend response. Although the role played by dissociation in the tend-and-befriend response is unknown, it appears that both are associated with a suppression of SNS activity, and dissociation seems to often co-occur with affiliative behaviour. Whether sensitisation of the tend-and-befriend response and dissociative reactions make up separate or combined pathways to PTSD is unknown. However, such pathways may be mediated by risk factors such as social support, dissociation, and possibly emotion-focused coping. Testosterone and oestrogen levels are not hypothesised to be affected by trauma exposure in the model. Rather, they should be viewed as ways in which sex may influence the initial stress response in males and females. Even though there are obvious differences in the distribution of sex hormones, both oestrogen and testosterone are present and may influence the stress response in both sexes. Thus, although the tend-andbefriend response is hypothesised to dominate in females and the fight-or-flight response is hypothesised to dominate in males, both response patterns and the associated pathways to PTSD may exist in both sexes.

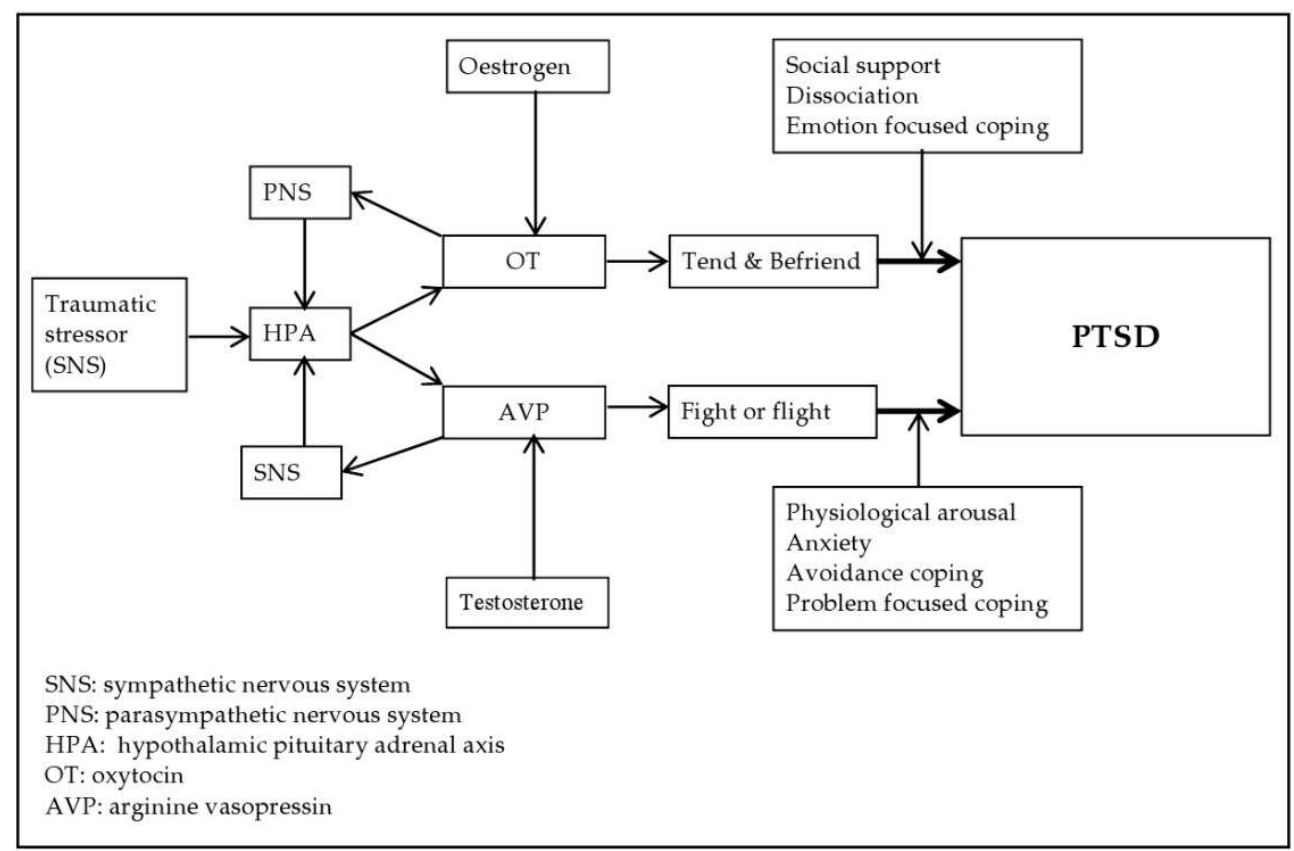

Fig. 1. A model of potential sex differences in initial stress response and pathways to PTSD

On a final note, the hypothesised involvement of oxytocin and social support in the development of PTSD in females should not be taken to suggest that the release of oxytocin and support seeking behaviour are maladaptive. In fact, higher oxytocin levels have been associated with faster HPA recovery in females after an acute stress laboratory challenge (Olff et al., 2007). Thus, it is most likely that it is a dysregulated oxytocin response which is related to PTSD in females, possibly because the downregulation of the SNS associated with the secretion of oxytocin may trigger dissociative reactions, which appear to be directly 
associated with the later development of PTSD (e.g. Ozer et al., 2003). Furthermore, because oxytocin appears to play a greater role in the female stress response as well as in other aspects of female behaviour, females are likely to be more vulnerable to dysregulation of the oxytocin system than males. Similarly, it is not the tend-and-befriend response in and of itself that leads to higher rates of PTSD in females. Rather, it has been suggested that PTSD develops when the tend-and-befriend response is compromised (Olff et al., 2007). This idea is consistent with studies suggesting that social support serves as a protective factor to a greater extent in females than what appears to be the case in males. Thus, it is possible that females rely on the tend-and-befriend response as protection against stressors, but when it is not possible to seek protection among others, as is often the case with interpersonal assault, the same physiological processes underlying the tend-and-befriend response may lead to dissociation as an alternative protection against the stressor. Thus, the females stress response may be more vulnerable to outside influences (e.g. a perpetrator who does not respond to the pleas of the victim or significant others who fail to understand the victim's distress) than the male stress response. This may be part of the reason why females appear to be more vulnerable to the negative sequalae of trauma.

Finally, it should be mentioned that moderation effects have been reported in relation to other risk factors not reported here. For example, depression, negative affectivity/ neuroticism, and younger age have sometimes been reported to be related to PTSD in females more than in males, whereas prior traumatic exposure has been reported to predict PTSD in males only (for an overview see Christiansen \& Elklit, 2008). Sex differences in such risk factors do not appear to fit easily in the model introduced above. In fact, depression has been linked to increased SNS activity (Veith et al., 1994) as well as HPA hyper-reactivity (Pariante \& Lightman, 2008). In the proposed model, PTSD in females is associated with a suppression of SNS activity and hypo-reactivity in the HPA axis, and it is thus unclear why depression should be particularly related to PTSD in females. More research on sex differences in the physiological correlates of PTSD as well as depression is needed in order to understand these apparently contradictory results. Furthermore, based on data from the NCS, Bromet, Sonnega, and Kessler (1998) reported that more risk factors predicted PTSD in female than male trauma survivors. Similarly, King and colleagues (1999) reported that the relative importance of pre-, peri-, and post-traumatic variables in predicting PTSD differed for male and female Vietnam veterans. These findings suggest not only that the relationship between different risk factors and the presence or severity of PTSD may be different for males and females, but also that we have identified more of the risk factors involved in the development of PTSD in females than in males. Therefore, in order to better understand and prevent the development of PTSD, more studies need to examine risk factors on PTSD separately in males and females.

Even though gender based theories may account for mediation effects of sex in PTSD, such as why females use more emotion-focused coping strategies, we do not believe that genderspecific socialisation and differences in the daily stressors that males and females are exposed to are likely to account for the moderation effects of sex in PTSD, which have been discussed here. Such moderation effects are more likely to arise from sex differences in the physiological response to stress and its sequalae. For example, isolation has been reported to serve as a stressor in female but not male rats. Similarly being with other rats has been found to reduce the adverse effects of chronic foot shock stress in female rats, while increasing such effects in males (Westenbroek et al, 2003). This suggests that sex differences 
in the beneficial effects of social support cannot fully be accounted for by gender differences. Instead, such results are consistent with an evolutionary pressure towards a tend-andbefriend response in females. However, whereas evolutionary-based sex differences in the initial stress response may best account for any consistent sex differences in different pathways to PTSD, the results reviewed here suggest that although there may be sex differences in the importance of the different risk factors, none of them appeared to be uniquely associated with either males or females. Thus, the different risk factors are likely to work together in very complex ways, and whether any particular individual follows a specific pathway to PTSD is likely to depend upon a number of different factors, including biology, contextual factors, and gender role. We believe that the role played by sex in the development of PTSD is one of mediated moderation, with sex influencing both the distribution of risk and protective factors and the relationship between such factors and the development and severity of PTSD.

\section{Two disorders or one? Sex differences in the expression of traumatisation}

When the PTSD diagnosis was introduced into the DSM-III (American Psychiatric Association, 1980), the different syndromes created to describe the symptoms reported by male war veterans and female survivors of rape and domestic violence were combined. However, if males and females follow different pathways to PTSD, which are mediated by different risk factors, it is possible that there are sex differences in the symptomatology of PTSD. It may therefore be time to reconsider, whether the post-traumatic symptomatology experienced by males and females is best captured by the present PTSD diagnosis, or whether we should go back to diagnosing trauma victims according to sex-specific syndromes. However, this question may prove very difficult to answer. Whereas numerous studies have examined sex differences in exposure to trauma and in the prevalence and severity of PTSD, sex differences in the expression of PTSD have been less extensively studied.

Preliminary support has been reported for a dissociative subtype of PTSD, which is associated with diminished physiological reactivity, and which may be more common in females than in males (Griffin et al., 1997; Olff et al., 2007). Furthermore, there is some support for the hypothesis that males and females with PTSD differ on measures of arousal and HPA disturbances. Although HPA activity is greater among healthy females than healthy males in response to acute stressors, studies have shown that male MVA victims with PTSD appear to have greater HPA arousal than females, although both sexes still display lower overall arousal levels than healthy controls (Paris et al., 2010). Based on these findings, it would be easy to assume, that males will score higher on symptoms of arousal than females. However, as mentioned earlier females experience more PTSD symptoms across all three symptom clusters than do males. The reason for this may be that arousal in PTSD research is often used to cover a wide range of increases in physiological activity. However, certain types of arousal may be associated with PTSD, whereas others may not. For example, PTSD in males has been reported to be related to elevated heart rate but not blood pressure (Bryant et al., 2000; Shalev et al., 1998), and it has been suggested that this is due predominantly to adrenergic rather than noradrenergic activation. Therefore, when considering the specific role of physiological arousal in male compared to female PTSD, it is important to note that the increased acute arousal, which may be associated with increased PTSD severity at later stages, may not be the same type of arousal as that included in the DSM-IV PTSD diagnosis (Hawk et al., 2000). 
One study has found that males and females seeking treatment for PTSD related to interpersonal assault expressed comparable levels of PTSD severity, depression, guilt, and trait anger (Galovski et al., 2011). However, the same study found that males reported higher levels of state anger and females reported more health-related complaints. Unfortunately, symptoms of dissociation and physiological arousal were not included in this study. The findings suggest that there are minor differences in relation to features associated with PTSD in males and females, but that PTSD levels are comparable. In accordance with this view, it has been reported that males and females with PTSD show equal levels of functional impairment (Schonfeld et al., 1997). However, despite presenting with PTSD symptomatology very similar to that in females, the increased levels of state anger in males suffering from PTSD may result in specific problems. If males respond with anger when being reminded of the trauma, they may be more likely than females to push others away. PTSD constitutes a burden to the friends and family of the person suffering from PTSD and may lead to decreases in support availability over time (Jakupcak et al., 2006; Kaniasty \& Norris, 2008). Although both males and females with PTSD may experience a decrease in social support as their symptoms persist, this phenomenon has been particularly reported for male combat veterans with PTSD (Kaniasty \& Norris, 2008). In contrast, an increase in health-related complaints is less likely to result in the withdrawal of support and may in fact cause females to seek more support from both health professionals and informal support sources. Longitudinal studies are needed to illuminate how the relationship between social support and PTSD develops over time, and whether such developments differ between males and females. For example, it is possible that social support is a better predictor of PTSD symptomatology in females, but that PTSD leads to greater deterioration of social support in males.

In accordance with the relative similarity in symptomatology found in males and females with PTSD, studies of comorbidity generally find more similarities than differences. One study on treatment seeking patients with PTSD reported that males and females presented with fairly comparable clinical profiles overall, but that males with PTSD experienced more comorbid disorders than did females, particularly substance abuse and antisocial personality disorder (APD; Zlotnick et al., 2001). De Bellis \& Keshavan (2003) have demonstrated that males show evidence of more adverse neurobiological consequences of childhood trauma than do females, and that PTSD related to childhood maltreatment appears to be more strongly associated with conduct disorder and criminal offences in males than in females. It is therefore possible that the increased prevalence of APD in males compared to females with PTSD may be particularly apparent in relation to childhood trauma. However, we have no knowledge of any studies examining this possibility. Research on sex differences in comorbidity is scarce as most comorbidity research has been conducted on male samples or has not looked at sex differences.

Although the studies mentioned above suggest that males and females display similar symptoms of post-traumatic stress, such findings have been based on participants already diagnosed with PTSD. It is possible that males tend to exhibit posttraumatic symptomatology other than the re-experiencing, avoidance, and arousal symptoms captured by the PTSD diagnosis, and that this can account for why there are more females than males with PTSD. As mentioned above, PTSD is more often associated with APD in males than in females. However, this sex difference in APD is also found in the general population (Cale \& Lilienfeld, 2002). As APD has been repeatedly reported to be related to childhood trauma (Lobbestael \& Arntz, 2010), it may be a common way for post-traumatic 
symptomatology to be expressed in males independently of the PTSD diagnosis. Although irritability and aggressive outbursts are not uncommon in people suffering from PTSD, particularly in males, the remaining symptoms are mostly internalising. It has been reported that females are more likely to suffer from internalising disorders such as anxiety disorders and depression, whereas males are more likely to suffer from externalising disorders, such as substance abuse or conduct disorder in the general population (Kessler et al., 1995) and following traumatic exposure (Pratchett et al., 2010). Similarly, although results have been mixed, increases in substance abuse have been registered primarily in male trauma survivors, whereas increases in somatisation, anxiety, and suicide attempts have been documented primarily in female trauma victims (Tolin \& Foa, 2008). Furthermore, PTSD in females tends to be more chronic than in males, and females are more prone to develop complex PTSD. The concept of complex PTSD was specifically developed to capture posttraumatic symptoms other than the ones included in the PTSD diagnosis following prolonged and chronic trauma (Cloitre et al., 2002). Complex PTSD covers symptoms similar to those associated with borderline personality disorder (e.g. impulsivity, aggression, self-destructive behaviour, dissociation, and interpersonal problems) as well as feelings of alienation and trust issues (Cloitre et al., 2002).

In sum, there appear to be some sex differences on measures of physiological arousal, state anger, dissociation, somatisation, and personality disorders. Such differences are likely to be caused by a combination of gender differences in how males and females express symptomatology and sex differences in how trauma affects brain development. However, it appears that even though females are at a higher risk of developing PTSD than males, once males do develop PTSD their overall symptomatology does not appear to differ much from that found in females. This suggests that although males and females appear to differ in their initial trauma response and may follow different pathways to PTSD, there is at present no support for the idea that the symptomatology of male and female trauma victims is best captured by more sex-specific syndromes. However, more research focusing on sex differences once PTSD has developed is needed in order to draw any conclusions in relation to this question, especially as both males and females also display some sex-specific symptomatology (e.g. complex PTSD, antisocial personality disorder), which is not fully captured by the PTSD diagnosis.

\section{Clinical implications of sex differences in PTSD}

If males and females differ in their expression of PTSD symptomatology, it follows that they may respond differently to treatment. Even if there are no major differences in symptomatology, sex differences in the risk and protective factors associated with the development and maintenance of PTSD may still result in sex differences in treatment outcome. Finally, males and females may differ in how comfortable they feel in different treatment settings and with different treatment paradigms. It has been suggested that gender socialisation plays a role in the treatment of PTSD, and that males express less affect and are more cognitively oriented in therapy than females (Cason et al., 2002). It could be argued that such behaviour represents problem-focused coping and is consistent with activation of the fight-or-flight system.

Based on the idea that different pathways lead to PTSD in males and females, and that different risk factors may thus be important for the development of PTSD in the two sexes as illustrated in Figure 1, it might be expected that females will benefit more from therapy, 
which aims to reduce levels of dissociation and increase levels of social support. In contrast, a therapeutic approach, which aims to reduce physiological arousal and dampen anxiety may be more beneficial to males. In accordance with these ideas, a recent pilot study has indicated that propranolol, a beta-blocker known to reduce heart rate and blood pressure, may decrease PTSD severity in males but increase PTSD severity in females (Nugent et al., 2010). Whereas there is some support for the hypothesis that emotion-focused coping is more beneficial in females than in males, it is possible that males as well as females will benefit more from a therapeutic approach, which aims to strengthen the coping strategies, which they do not automatically use. The idea is, that once PTSD has developed, it appears that the preferred coping strategies have proved ineffective. Some support has been reported for this idea in grief counselling, as problem-focused counselling was found to be more effective in females compared to males, whereas an emotion-focused intervention form appeared to be more effective in males compared to females 11 months postbereavement. However, such sex differences may not be transferable to less chronic populations or to PTSD treatment.

Finally, an important implication of the influence of multiple factors on HPA reactivity is the possibility that the disturbed HPA reactivity found in patients with PTSD can be treated through either pharmacological, psychotherapeutic, or social interventions. The efficacy of different treatment strategies may therefore not be dependent on what caused the HPA disturbances in the first place. Unfortunately, sex differences in treatment outcome are grossly understudied. Many PTSD treatment effect studies are based on sex-specific trauma samples, such as war veterans and sexual assault victims. Furthermore, of the few studies, which do include both-sex samples, few examine the impact of sex on treatment efficacy. As a result, little is known about whether the same treatments are equally effective (or noneffective) in males and females. Blain, Galovski, and Robinson (2010) reviewed the literature on sex differences in response to treatment and found only nine randomised controlled trials, which assessed sex differences in primary PTSD treatment outcome. Most of these studies were based on samples, which were too small to detect minor sex differences. Furthermore, 6/9 studies were based on samples exposed to a variety of trauma types, and not a single study examined sex differences in treatment outcome following interpersonal violence. Results from randomised as well as non-randomised clinical trials were mixed regarding the impact of sex on treatment outcome. The majority of studies reported no sex differences, but others found that females may respond better to trauma focused therapy than males, and that males may be more likely to drop out of treatment. However, more than anything this review highlights the need for more research in the area.

\section{Future research on sex differences in PTSD}

As stated earlier, we believe that the research on sex differences in PTSD is still in its childhood. Consistent sex differences still remain to be documented following certain types of trauma (e.g. sexual assault, combat exposure). Furthermore, the degree to which sex differences in risk factors associated with PTSD may account for the increased vulnerability of PTSD in females is still unknown and deserves more attention. However, future research should move beyond simply focusing on establishing and explaining sex differences in exposure and PTSD.

Sex differences have been reported in the initial response to threat, but the degree to which the tend-and-befriend response is dominant in females in response to specifically traumatic 
stressors remains to be documented across trauma types. One study of sex differences in the stress response of young children reported that sex differences were only significant under high levels of stress (David \& Lyons-Ruth, 2005). This suggests that sex differences may exist in response to traumatic incidents and in the development of PTSD, which may not necessarily be detectable under lower levels of stress. Therefore, research on sex differences in PTSD and in the initial response to trauma should rely less on studies of non-traumatic stressors, such as the ones set up in laboratories, and instead focus more on the male and female response to actual trauma, both in the peritraumatic and post-traumatic phases.

While there is some support for the existence of different pathways to PTSD in children, such pathways remain to be confirmed in adults. Particularly, it is up to future research to establish how many pathways may exist, and whether males and females tend to follow different pathways to PTSD. Different pathways are likely to stem from different physiological and behavioural reactions in the acute trauma phase and to be mediated by different risk factors. Thus, the degree to which physiological systems, which are activated in the face of trauma, are sensitised in trauma victims with and without PTSD remains to be examined.

Although research has identified numerous risk factors associated with PTSD in both sexes, there are some indications that such risk factors may not predict PTSD equally well in males and females, and more studies need to focus on sex as a possible moderator of the impact of risk factors on PTSD development. The model proposed in the present chapter suggests that moderation effects may be particularly likely to be found for emotional support, physiological arousal, anxiety, dissociation, and coping. However, research should by no means be limited to these risk factors, as there may exist numerous pathways to PTSD, all of which may be moderated by sex. Haines, Beggs, and Hurlbert (2008) argued that even if sex only has a small moderating effect on the relationship between different risk factors and PTSD, such effects are still important to identify. Even small sex differences may point to different mechanisms involved in the development of PTSD in males and females, and such different mechanisms may call for different intervention strategies. Finally, as stated earlier, it appears that we have identified more of the risk factors involved in the development and maintenance of PTSD in females than in males. This suggests, that important risk factors related to the development of PTSD in males remain to be identified. It is our belief that by routinely including peritraumatic physiological arousal as a risk factor of PTSD, more variance in the symptomatology of males can be accounted for.

Furthermore, sex differences in symptomatology once PTSD has developed need to be examined. In particular, males and females with PTSD could be expected to differ on levels of dissociation and physiological arousal, and these two variables should be included in future studies on posttraumatic symptomatology in males and females. Research on sex differences in PTSD should include differences in symptomatology not covered by the PTSD diagnosis, in order to help us understand how the symptomatology of male and female trauma victims is best categorised, assessed, and treated.

As mentioned in the beginning of this chapter, most studies claiming to study gender have in fact studied sex. The extent to which gender roles, masculinity and femininity, sexuality, and other gender related concepts play a role in the development and maintenance of PTSD remains to be studied. Such variables may be relevant in relation to PTSD prevalence, initial stress response, different pathways to PTSD, symptomatology, and treatment efficacy. Any moderation effects which sex may have on the relationship between other risk factors and PTSD are likely to be affected by gender. 
Finally, although sex is generally thought of as a relatively simple concept, different levels of the sex hormones (including oxytocin and AVP) included in the model presented in this chapter vary within each sex as well as between males and females. Thus, one last question for future research to answer, is how much sex differences in PTSD are affected by intra-sex variations in levels of testosterone, oestrogen, AVP, and oxytocin. In particular, the female menstrual cycle as well as the use of oral contraceptives have been reported to affect secretion of free cortisol levels in response to stressors (Biondi \& Picardi, 1999; Kirschbaum et al., 1999). In fact, it has been suggested that prolonged use of oral contraceptives may alter the reaction of the HPA axis to psychological stress (Biondi \& Picardi, 1999). We suggest that the impact of such intra-sex variations on the development of PTSD should be more closely examined in future studies.

\section{Conclusion}

In conclusion, although numerous studies have been published on sex or gender differences in PTSD, most have focused on establishing and explaining sex differences in PTSD prevalence. There is general consensus that females are approximately twice as likely as males to be diagnosed with PTSD following a wide range of trauma types, although sex differences in the prevalence of PTSD following some trauma types (e.g. rape, CSA, combat) have not been fully established. Sex differences in the types of trauma that males and females are exposed to and in the risk factors associated with PTSD appear to account for at least some of the increased PTSD prevalence in females compared to males. However, more research is needed to establish the degree to which sex differences in PTSD prevalence and severity is mediated by trauma type and risk factors, which are more prevalent in females. In this chapter we have gone beyond simply focusing on sex differences in the prevalence of PTSD and have examined how sex differences in the acute response to trauma may cause males and females to follow different pathways to PTSD. There is some evidence that whereas males tend to react to trauma with the well-known fight-or-flight response, females may be more prone to react with a tend-and-befriend response. These two distinct responses to stress are associated with marked physiological differences in SNS, PNS, and HPA activity. Dysregulation of these systems may lead to sensitisation of the fight-or-flight response in males and the tend-and-befriend response in females. This may result in males and females following separate pathways to PTSD. There is some support for the existence of such pathways, as preliminary findings suggest that sex may serve as a moderator on the relationship between certain risk factors and PTSD. In this chapter we have reviewed some support for the hypothesis that physiological arousal and possibly anxiety may be more closely associated with the development of PTSD in males compared to females. In contrast, some studies have found that social support and dissociation are more closely linked to the development of PTSD in females. Sex differences in the relationship between coping and PTSD may exist but are less well documented.

Despite sex differences in the initial response to trauma and risk factors associated with PTSD, there do not appear to be major differences in the core symptomatology of PTSD in treatment seeking males and females. However, there is some evidence that males may experience more physiological arousal and anger, whereas females report more dissociation and somatisation. Although the combined impact of multiple variables on the reactivity of the HPA axis makes it theoretically possible for males and females to primarily follow different pathways to PTSD, the end result appears to be similar, although sex differences in 
posttraumatic symptomatology need to be studied further. Such research is particularly needed for symptomatology not covered by the PTSD diagnosis.

Finally, although different risk factors associated with PTSD as well as minor differences in symptoms such as anger and somatisation may call for different therapeutic approaches, sex differences in the efficacy of different PTSD treatments remain to be studied. However, the HPA axis appears to be influenced by multiple factors of both biological and social origin. This suggests that the core disturbances in PTSD may be treated through either biological, psychotherapeutic, or social interventions, regardless of the different pathways which may have caused it.

It is difficult to discern whether sex differences in PTSD are best accounted for by sex or by gender-based theories. We believe it to be most likely, that sex and gender differences work together to account for the increased prevalence and severity of PTSD in females compared to males, as well as the other sex differences in PTSD. It is therefore unlikely that scientists will ever be able to fully account for the unique influence of either. Many gender differences in society are likely to build on pre-existing sex differences related to differences in brain structure and functioning, physiological response to stress, and the influence of sex hormones on the different areas of human functioning. In contrast, the extent to which sex differences come to affect the actual behaviour of males and females may be affected by cultural factors, such as gender role expectancies, which can explain why the extent of sex differences in PTSD appear to vary between cultures (Norris et al., 2001).

As stated in a report by the Institute of Medicine on the biological contributions to human health: "sex matters and until the question of sex is routinely asked and the results - positive or negative - are routinely reported, many opportunities to obtain a better understanding of the pathogenesis of disease and to advance human health will surely be missed (Wizemann \& Pardue, 2001).

\section{References}

Ahern, J., Galea, S., Fernandez, W. G., Koci, B., Waldman, R., \& Vlahov, D. (2004). Gender, social support, and posttraumatic stress in postwar Kosovo. Journal of Nervous and Mental Disease, 192(11), 762-770.

American Psychiatric Association. (1980). Diagnostic and statistical manual of mental disorders (3rd ed.). Washington, DC: Author.

American Psychiatric Association. (2000). Diagnostic and statistical manual of mental disorders (4th ed., Text Revision). Washington, DC: Author.

Andrews, B., Brewin, C. R., \& Rose, S. (2003). Gender, social support, and PTSD in victims of violent crime. Journal of Traumatic Stress, 16(4), 421-427.

Araya, M., Chotai, J., Komproe, I. H., \& de Jong, J. T. V. M. (2007). Effect of trauma on quality of life as mediated by mental distress and moderated by coping and social support among postconflict displaced Ethiopians. Quality of Life Research, 16, 915-927.

Banyard, V. L. \& Graham-Bermann, S. A. (1993). Can women cope? A gender analysis of theories of coping with stress. Psychology of Women Quarterly, 17, 303-318.

Biondi, A. \& Picardi, A. (1999). Psychological stress and neuroendocrine function in humans: The last two decades of research. Psychotherapy and Psychosomatics, 68, 114-150.

Blain, L. M., Galovski, T. E., \& Robinson, T. (2010). Gender differences in recovery from posttraumatic stress disorder: A critical review. Aggression and Violent Behavior, 15, $463-474$. 
Blanchard, E. B., Hickling, E. J., Galovski, T., \& Veazey, C. (2002). Emergency room vital signs and PTSD in a treatment, seeking sample of motor vehicle accident survivors. Journal of Traumatic Stress, 15(3), 199-204.

Bödvarsdóttir, I. \& Elklit, A. (2004). Psychological reactions in Icelandic earthquake survivors. Scandinavian Journal of Psychology, 45(1), 3-13.

Breslau, N., Davis, G. C., Andreski, P., Peterson, E. L., \& Schultz, L. R. (1997). Sex differences in posttraumatic stress disorder. Archives of General Psychiatry, 54, 1044-1048.

Breslau, N., Kessler, R. C., Chilcoat, H. D., Schultz, L. R., Davis, G. C., \& Andreski, P. (1998). Trauma and posttraumatic stress disorder in the community: The Detroit area survey of trauma. Archives of General Psychiatry, 55, 626-632.

Bromet, E., Sonnega, A., \& Kessler, R. C. (1998). Risk factors for DSM-III-R posttraumatic stress disorder: Findings from the National Comorbidity Survey. American Journal of Epidemiology, 147(4), 353-361.

Bryant, R. A. \& Harvey, A. G. (2003). Gender differences in the relationship between acute stress disorder and posttraumatic stress disorder following motor vehicle accidents. Australian and New Zealand Journal of Psychiatry, 37(2), 226-229.

Bryant, R. A., Harvey, A. G., Guthrie, R. M., \& Moulds, M. (2000). A prospective study of psychophysiological arousal, acute stress disorder, and posttraumatic stress disorder. Journal of Abnormal Psychology, 109(2), 341-344.

Cale, E. M. \& Lilienfeld, S. O. (2002). Sex differences in psychopathy and antisocial personality disorder: A review and integration. Clinical Psychology Review, 22, 1179-1207

Cason, D., Grubaugh, A., \& Resick, P. (2002). Gender and PTSD treatment: Efficacy and effectiveness, in Gender and PTSD, Kimerling, R., Ouimette, P., \& Wolfe, J., pp. 305334, The Guilford Press, ISBN: 1-57230-783-8, NY.

Christiansen, D. M. \& Elklit, A. (2008). Risk factors predict post-traumatic stress disorder differently in men and women. Annals of General Psychiatry, 7, 24.

Chung, H. \& Breslau, N. (2008). The latent structure of post-traumatic stress disorder: Test of invariance by gender and trauma type. Psychological Medicine, 38, 563-573.

Cloitre, M., Koenen, K. C., Gratz, K. L., \& Jakupcak, M. (2002). Differential diagnosis of PTSD in women, in Gender and PTSD, Kimerling, R., Ouimette, P., \& Wolfe, J., pp. 117-149, The Guilford Press, ISBN: 1-57230-783-8, NY.

Cottler, L. B., Nishith, P., \& Compton, W. M., 3rd. (2001). Gender differences in risk factors for trauma exposure and post-traumatic stress disorder among inner-city drug abusers in and out of treatment. Comprehensiv Psychiatry, 42(2), 111-117.

Cromer, L. DM. \& Smyth, J. M. (2010). Making meaning of trauma: Trauma exposure doesn't tell the whole story. Journal of Contemporary Psychotherapy, 40, 65-72.

David, D. H. \& Lyons-Ruth, K. (2005). Differential attachment responses of male and female infants to frightening maternal behavior: Tend or befriend versus fight or flight? Infant Mental Health Journal, 26(1), 1-18.

Davis, M. \& Emory, E. (1995). Sex differences in neonatal stress reactivity. Child Development, $66,14-27$.

De Bellis, M. D. \& Keshavan, M. S. (2003). Sex differences in brain maturation in maltreatment-related pediatric posttraumatic stress disorder. Neuroscience and Biobehavioral Reviews, 27(1-2), 103-117.

Ehlers, A., Mayou, R. A., \&, Bryant, B. (1998). Psychological predictors of chronic posttraumatic stress disorder after motor vehicle accidents. Journal of Abnormal Psychology, 107, 508-519. 
Ehring, T., Ehlers, A., \& Glucksman, E. (2006). Contribution of cognitive factors to the prediction of post-traumatic stress disorder, phobia and depression after motor vehicle accidents. Behaviour Research and Therapy 44, 1699-1716.

Elklit, A. (1996). Coping Style Questionnaire: A contribution to the validation of a scale for measuring coping strategies. Personality and Individual Differences, 21, 809-812.

Elklit, A. \& Christiansen, D. M. (in press). Risk factors for PTSD in female help-seeking victims of sexual assault. Violence and Victims.

Elklit, A. \& O'Connor, M. (2005), Post-traumatic stress disorder in a Danish population of elderly bereaved. Scandinavian Journal of Psychology, 46, 439-445.

Farhood, L., Zurayk, H., Chaya, M., Saadeh, F., Meshefedjian, G., \& Sidani, T. (1993). The impact of war on the physical and mental health of the family: The Lebanese experience. Social Science Medicine, 36(12), 1555-1567.

Folkman, S. \& Moskowitz, J. T. (2004). Coping: Pitfalls and promise. Annual Review of Psychology, 55, 745-774.

Fullerton, C. S., Ursano, R. J., Epstein, R. S., Crowley, B., Vance, K., Kao, T. C., Dougall, A., \& Baum, A. (2001). Gender differences in posttraumatic stress disorder after motor vehicle accidents. American Journal of Psychiatry, 158(9), 1486-1491.

Galovski, T. E., Mott, J., Young-Xu, Y. N., \& Resick, P. A. (2011). Gender differences in the clinical presentation of PTSD and its concomitants in survivors of interpersonal assault. Journal of Interpersonal Violence, 26(4), 789-806.

Gavranidou, M. \& Rosner, R. (2003). The weaker sex? Gender and post-traumatic stress disorder. Depression and Anxiety, 17(3), 130-139.

Gavrilovic, J., Lecic-Tosevski, D., Dimic, S., Pejovic-Milovancevic, M., Knezevic, G., \& Priebe, S. (2003). Coping strategies in civilians during air attacks. Social Psychiatry and Psychiatric Epidemiology, 38(3), 128-133.

Geary, D. C. \& Flinn, M. V. (2002). Sex differences in behavioral and hormonal response to social threat: Commentary on Taylor et al. (2000). Psychological Review, 109(4), 745750 .

Gil, S. (2005). Coping style in predicting posttraumatic stress disorder among Israeli students. Anxiety Stress and Coping, 18(4), 351-359.

Goldberg, L. R. \& Freyd, J. J. (2006). Self-reports of potentially traumatic experiences in an adult community sample: Gender differences and test-retest stabilities of the items in a brief betrayal-trauma survey. Journal of Trauma and Dissociation, 7(3), 39-63.

Griffin, M. G., Resick, P. A., \& Mechanic, M. B. (1997). Objective assessment of peritraumatic dissociation: Psychophysiological indicators. American Journal of Psychiatry, 154(8), 1081-1088.

Grillon, C. (2008). Models and mechanisms of anxiety: Evidence from startle studies. Psychopharmacology, 199, 421-437.

Haines, V. A., Beggs, J. J., \& Hurlbert, J. S. (2008). Contextualizing health outcomes: Do effects of network structure differ for women and men? Sex Roles, 59(3-4), 164-175.

Hapke, U., Schumann, A., Rumpf, H. J., John, U., \& Meyer, C. (2006). Post-traumatic stress disorder: The role of trauma, pre-existing psychiatric disorders, and gender. European Archives of Psychiatry and Clinical Neuroscience, 256(5), 299-306.

Hawk, L. W., Dougall, A. L., Ursano, R. J., \& Baum, A. (2000). Urinary catecholamines and cortisol in recent-onset posttraumatic stress disorder after motor vehicle accidents. Psychosomatic Medicine, 62(3), 423-434. 
Hettema, J. M., Prescott, C. A., \& Kendler, K. S. (2004). Genetic and environmental sources of covariation between generalized anxiety disorder and neuroticism. American Journal of Psychiatry, 161(9), 1581-1587.

Hovanitz, C. A. \& Kozora, E. (1989). Life stress and clinically elevated MMPI-scales: Gender differences in the moderating influence of coping. Journal of Clinical Psychology, 45(5), 766-777.

Irish, L. A., Fischer, B., Fallon, W., Spoonster, E., Sledjeski, E. D., \& Delahantya, D. L. (2011). Gender differences in PTSD symptoms: An exploration of peritraumatic mechanisms. Journal of Anxiety Disorders 25, 209-216.

Jakupcak, M., Osborne, T. L., Michael, S., Cook, J. W., \& McFall, M. (2006). Implications of masculine gender role stress in male veterans with posttraumatic stress disorder. Psychology of Men E Masculinity, 7(4), 203-211.

Kaniasty, K. \& Norris, F. H. (2008). Longitudinal linkages between perceived social support and posttraumatic stress symptoms: Sequential roles of social causation and social selection. Journal of Traumatic Stress, 21(3), 274-281.

Kaplow, J. B., Dodge, K. A., Amaya-Jackson, L., \& Saxe, G. N. (2005). Pathways to PTSD, part II: Sexually abused children. American Journal of Psychiatry, 162(7), 1305-1310.

Kendler, K. S., Kuhn, J., \& Prescott, C. A. (2004). The interrelationship of neuroticism, sex, and stressful life events in the prediction of episodes of major depression. American Journal of Psychiatry, 161(4), 631-636.

Kessler, R. C., McGonagle, K. A., Zhao, S., Nelson, C. B., Hughes, M., Hughes, S., Wittchen, H., \& Kendler, K. S. (1994). Lifetime and 12-Month Prevalence of DSM-III-R Psychiatric Disorders in the United States: Results from the National Comorbidity Survey. Archives of General Psychiatry, 51, 8-19.

Kessler, R. C., Sonnega, A., Bromet, E., Hughes, M., \& Nelson, C. B. (1995). Posttraumatic stress disorder in the National Comorbidity Survey. Archives of General Psychiatry, 52(12), 1048-1060.

King, D. W., King, L. A., Foy, D. W., Keane, T. M., \& Fairbank, J. A. (1999). Posttraumatic stress disorder in a national sample of female and male Vietnam veterans. Risk factors, war-zone stressors, and resilience-recovery variables. Journal of Abnormal Psychology, 108(1), 164-170.

Kirmayer, L. J., Robbins, J. M., \& Paris, J. (1994). Somatoform disorders: Personality and the social matrix of somatic distress. Journal of Abnormal Psychology, 103(1), 125-136.

Kirschbaum, C., Kudielka, B. M., Gaab, J., Schommer, N. C., \& Hellhammer, D. H. (1999). Impact of gender, menstrual cycle phase, and oral contraceptives on the activity of the hypothalamus-pituitary-adrenal axis. Psychosomatic Medicine, 61(2), 154-162.

Kivlighan, K. T., Granger, D. A., \& Booth, A. (2005). Gender differences in testosterone and cortisol response to competition. Psychoneuroendocrinology, 30(1), 58-71.

Klein, L. C. \& Corwin, E. J. (2002). Seeing the unexpected: How sex differences in stress responses may provide a new perspective on the manifestation of psychiatric disorders. Current Psychiatry Reports, 4, 441-448.

Koenen, K. C. \& Widom, C. S. (2009). A prospective study of sex differences in the lifetime risk of posttraumatic stress disorder among abused and neglected children grown up. Journal of Traumatic Stress, 22(6), 566-574.

Kudielka, B. M. \& Kirschbaum, C. (2005). Sex differences in HPA axis responses to stress: A review. Biological Psychology, 69(1), 113-132. 
Lilly, M. M., Pole, M., Best, S. R., Metzler, T., \& Marmar, C. R. (2009). Gender and PTSD: What can we learn from female police officers? Journal of Anxiety Disorders 23, 767774 .

Lobbestael, J. \& Arntz, A. (2010). Emotional, cognitive and physiological correlates of abuserelated stress in borderline and antisocial personality disorder. Behaviour Research and Therapy, 48, 116-124.

Lynn, R. \& Martin, T. (1997). Gender differences in extraversion, neuroticism, and psychoticism in 37 nations. Journal of Social Psychology, 137(3), 369-373.

McNally, R. J., Bryant, R. A., \& Ehlers, A. (2003). Does early psychological intervention promote recovery from posttraumatic stress? Psychological Science, 45-79.

Mollica, R. F., Caspi-Yavin, Y., Bollini, P., Troung, T., Tor, S., \& Lavelle, J. (1992). The Harward Trauma Questionnaire: Validating a cross-cultural instrument for measuring torture, trauma, and posttraumatic stress disorder in Indochinese refugees. The Journal of Nerveous ans Mental Disease, 180(2), 111-116.

Neumann, I. D. (2008). Brain oxytocin: A key regulator of emotional and social behaviours in both females and males. Journal of Neuroendocrinology, 20(6), 858-865.

Neumann, I. D., Wigger, A., Torner, L., Holsboer, F., \& Landgraf, R. (2000). Brain oxytocin inhibits basal and stress-induced activity of the hypothalamo-pituitary-adrenal axis in male and female rats: Partial action within the paraventricular nucleus. Journal of Neuroendocrinology, 12(3), 235-243.

Norris, F. H., Foster, J. D., \& Weisshaar, D. L. (2007). The epidemiology of sex differences in PTSD across developmental, societal, and research contexts, in Gender and PTSD, Kimerling, R., Ouimette, P., \& Wolfe, J., pp. 3-42, The Guilford Press, ISBN: 157230-783-8, NY.

Norris, F. H., Friedman, M. J., \& Watson, P. J. (2002). 60,000 disaster victims speak: Part II. Summary and implications of the disaster mental health research. Psychiatry, 65(3), 240-260.

Norris, F. H., Friedman, M. J., Watson, P. J., Byrne, C. M., Diaz, E., \& Kaniasty, K. (2002). 60,000 disaster victims speak: Part I. An empirical review of the empirical literature, 1981-2001. Psychiatry, 65(3), 207-239.

Norris, F. H., Perilla, J. L., Ibanez, G. E., \& Murphy, A. D. (2001). Sex differences in symptoms of posttraumatic stress: Does culture play a role? Journal of Traumatic Stress, 14(1), 7-28.

Nugent, N. R., Brown, N. C. C., Crow, J. P., Browne, L., Ostrowski, S., \& Delahanty, D. L. (2010). The efficacy of early propranolol administration at reducing PTSD symptoms in pediatric injury patients: A pilot study. Journal of Traumatic Stress, 23(2), 282-287.

O'Connor M. \& Elklit, A. (2008). Attachment styles, traumatic events, and PTSD: A crosssectional investigation of adult attachment and trauma. Attachment \& Human Development, 1 , 59-71.

Olff, M., Langeland, W., Draijer, N., \& Gersons, B. P. R. (2007). Gender differences in posttraumatic stress disorder. Psychological Bulletin, 133(2), 183-204.

Ozer, E. J., Best, S. R., Lipsey, T. L., \& Weiss, D. S. (2003). Predictors of posttraumatic stress disorder and symptoms in adults: A meta-analysis. Psychological Bulletin, 129(1), $52-$ 73.

Pariante, C. M. \& Lightman, S. L. (2008). The HPA axis in major depression: Classical theories and new developments. Trends in Neurosciences, 31(9), 464-468. 
Paris, J. J., Franco, C., Sodano, R., Freidenberg, B., Gordis, E., Anderson, D. A., Forsyth, J. P., Wulfert, E., \& Frye, C. A. (2010). Sex differences in salivary cortisol in response to acute stressors among healthy participants, in recreational or pathological gamblers, and in those with posttraumatic stress disorder. Hormones and Behavior $57,35-45$.

Peirce, J. M., Newton, T.L., Buckley, T. C., \& Keane, T.M. (2002). Gender and psychophysiology of PTSD, in Gender and PTSD, Kimerling, R., Ouimette, P., \& Wolfe, J., pp. 177-204, The Guilford Press, ISBN: 1-57230-783-8, NY.

Perry, B. D., Pollard, R. A., Blakley, T. L., Baker, W. L., \& Vigilante, D. (1995). Childhood trauma, the neurobiology of adaptation, and "use-dependent" development of the brain: How "states" become "traits". Infant Mental Health Journal, 16(4), 271-291.

Pratchett, L. C., Pelcovitz, M. R., \& Yehuda, R. (2010). Trauma and violence: Are women the weaker sex? Psychiatric Clinics of North America, 33(2), 465-474.

Ptacek, J. T., Smith, R. E., \& Zanas, J. (1992). Gender, appraisal, and coping: A longitudinal analysis. Journal of Personality, 60(4), 747-770.

Punamäki, R-L., Komproe, I. H., Quota, S., Elmasri, M., \& de Jong, J. T. V. M. (2005). The role of peritraumatic dissociation and gender in the association between trauma and mental health in a Palestinian community sample. American Journal of Psychiatry, 162(3), 545-551.

Ray, S. L. (2008). Evolution of posttraumatic stress disorder and future directions. Archives of Psychiatric Nursing, 22(4), 217-225.

Rosario, M., Shinn, M., Mørch, H., \& Huckabee, C. B. (1988). Differences in coping and social supports: Testing socialization and role constraint theories. Journal of Community Psychology, 16, 55-69.

Saxe, G. N., Stoddard, F., Hall, E., Chawla, N., Lopez, C., Sheridan, R., King, D., King, L., \& Yehuda, R. (2005). Pathways to PTSD, part I: Children with burns. American Journal of Psychiatry, 162(7), 1299-1304.

Schonfeld, W. H., Verboncoeura, C. J., Fifera, S. K., Lipschutz, R. C., Lubeck, D. P., \& Buesching, D. P. (1997). The functioning and well-being of patients with unrecognized anxiety disorders and major depressive disorder. Journal of Affective Disorders 43, 105-119.

Shalev, A. Y., Freedman, S., Peri, T., Brandes, D., Sahar, T., Orr, S. P., \& Pitman, R. K. (1998). Prospective study of posttraumatic stress disorder and depression following trauma. American Journal of Psychiatry, 155(5), 630-637.

Shumaker, S. A. \& Hill, D. R. (1991). Gender differences in social support and physical health. Health Psychology, 10(2), 102-111.

Simmons, C. A. \& Granvold, D. K. (2005). A cognitive model to explain gender differences in rate of PTSD diagnosis. Brief Treatment and Crisis Intervention, 5(3), 290-299.

Spindler, H., Elklit, A., \& Christiansen, D. M. (2010). Risk factors for posttraumatic stress disorder following an industrial disaster in a residential area: A note on the origin of observed gender differences. Gender Medicine 7(2), 156-165.

Spitzer, C., Klauer, T., Grabe, H-J., Lucht, M., Stieglitz, R-D., Schneider, W., \& Freyberger, H. J. (2003). Gender differences in dissociation: A dimensional approach. Psychopathology, 36, 65-70.

Stanton, A. L., Danoff-Burg, S., Cameron, C., \& Ellis, A. P. (1994). Coping through emotional approach: Problems of conceptualization and confounding. Journal of Personality and Social Psychology 66(2), 350-362. 
Stone, L. B., Gibb, B. E., \& Coles, M. E. (2010). Does the hopelessness theory account for sex differences in depressive symptoms among young adults? Cognitive Therapy Research, 34,177-187.

Swaab, D. F., Fliers, E., Hoogendijk, W. J., Veltman, D. J., \& Zhou, J. N. (2000). Interaction of prefrontal cortical and hypothalamic systems in the pathogenesis of depression. Progress in Brain Research, 126, 369-396.

Tamres, L. K., Janicki, D., \& Helgeson, V. S. (2002). Sex differences in coping behavior: A meta-analytic review and an examination of relative coping. Personality and Social Psychology Review, 6(1), 2-30.

Taylor, S. E. (2006). Tend-and-befriend: Biobehavioral bases of affiliation under stress. Current Directions in Psychological Science, 15(6), 273-277.

Taylor, S. E., Klein, L. C., Lewis, B. P., Gruenewald, T. L., Gurung, R. A. R., \& Updegraff, J. A. (2000). Biobehavioral responses to stress in females: Tend-and-befriend, not fight-or-flight. Psychological Review, 107(3), 411-429.

Taylor, S. E., Lewis, B. P., Gruenewald, T. L., Gurung, R. A. R., Updegraff, J. A., \& Klein, L. C. (2002). Sex differences in biobehavioral responses to threat: Reply to Geary and Flinn (2002). Psychological Review, 109(4), 751-753.

Tolin D. F. \& Foa, E. B. (2008). Sex differences in trauma and posttraumatic stress disorder: A quantitative review of 25 years of research, Psychological Trauma: Theory, Research, Practice, and Policy, S(1), 37-85.

Van der Kolk, B. A. (2007). The history of trauma in psychiatry. In Friedman, M. J., Keane, T. M., \& Resick, P. A., pp. 19-36, Handbook of PTSD. Guilford: New York.

Veith, R. C., Lewis, N., Linares, O. A., Barnes, R. F., Raskind, M. A., Villacres, E. C., Murburg, M. M., Ashleigh, E. A., Castillo, S., Peskind, E. R., Pascualy, M., \& Halter, J. B. (1994). Sympathetic nervous system activity in major depression: Basal and desipramine-induced alterations in plasma norepinephrine kinetics. Archives of General Psychiatry, 51, 411-422.

Wizemann, T. M. \& Pardue, M.-L. (Eds.). (2001). Committee on Understanding the Biology of Sex and Gender Differences, Board on Health Sciences Policy. Exploring the biological contributions to human health: Does sex matter? The National Academies Press. Washington, DC.

Westenbroek, C., Ter Horst, G. J., Roos, M. H., Kuipers, S. D., Trentani, A., \& den Boer, J. A. (2003). Gender-specific effects of social housing in rats after chronic mild stress exposure. Progress in Neuro-psychopharmacology and Biological Psychiatry, 27(1), 21-30.

Zeidner, M. (2006). Gender group differences in coping with chronic terror: The Israeli scene. Sex Roles, 54(3/4), 297-310.

Zetsche, U., Ehring, T., \& Ehlers, A. (2009). The effects of rumination on mood and intrusive memories after exposure to traumatic material: An experimental study. Journal of Behavior Therapy and Experimental Psychiatry, 40(4), 499-514.

Zlotnick, C., Zimmerman, M., Wolfsdorf, B. A., \& Mattia, J. I. (2001). Gender differences in patients with posttraumatic stress disorder in a general psychiatric practice. American Journal of Psychiatry, 158(11), 1923-1925. 


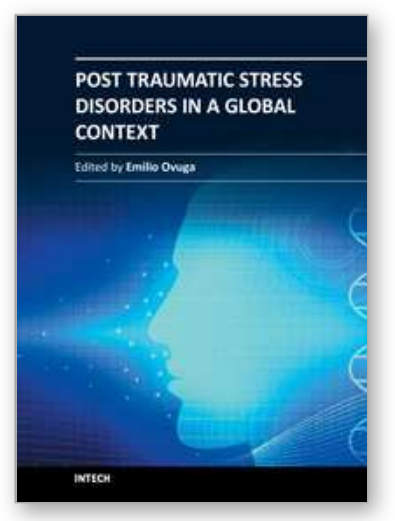

\author{
Post Traumatic Stress Disorders in a Global Context \\ Edited by Prof. Emilio Ovuga, Md, PhD
}

ISBN 978-953-307-825-0

Hard cover, 286 pages

Publisher InTech

Published online 20, January, 2012

Published in print edition January, 2012

If, as a health care or social service provider, one was called upon to help someone who has experienced terror in the hands of a hostage taker, an irate and chronically abusive spouse or parent, or a has survived a motor vehicle accident, landslide, earthquake, hurricane or even a massive flood, what would be one's priority response? What would be considered as the most pressing need of the individual requiring care? Whatever the answer to each of these questions, people who have experienced terror, suffer considerable psychological injury. Post-Traumatic Stress Disorder in a Global Context offers some answers to meet the needs of health care and socials service providers in all settings, whether in a hospital emergency room, at the war front, or natural disaster site. The take home message is, after providing emergency care, there is always a pressing need to provide mental health care to all victims of traumatic stress.

\title{
How to reference
}

In order to correctly reference this scholarly work, feel free to copy and paste the following:

Dorte Christiansen and Ask Elklit (2012). Sex Differences in PTSD, Post Traumatic Stress Disorders in a Global Context, Prof. Emilio Ovuga, Md, PhD (Ed.), ISBN: 978-953-307-825-0, InTech, Available from: http://www.intechopen.com/books/post-traumatic-stress-disorders-in-a-global-context/sex-differences-in-ptsd

\section{INTECH}

open science | open minds

\section{InTech Europe}

University Campus STeP Ri

Slavka Krautzeka 83/A

51000 Rijeka, Croatia

Phone: +385 (51) 770447

Fax: +385 (51) 686166

www.intechopen.com

\section{InTech China}

Unit 405, Office Block, Hotel Equatorial Shanghai

No.65, Yan An Road (West), Shanghai, 200040, China

中国上海市延安西路65号上海国际贵都大饭店办公楼 405 单元

Phone: +86-21-62489820

Fax: $+86-21-62489821$ 
(C) 2012 The Author(s). Licensee IntechOpen. This is an open access article distributed under the terms of the Creative Commons Attribution 3.0 License, which permits unrestricted use, distribution, and reproduction in any medium, provided the original work is properly cited. 